\title{
Study of Thermal Degradation of Biomass Wastes Generated from Palm Oil Milling Plant
}

\author{
Nugroho Dewayanto*, Anisa Najwa Azman, Nur Atiqah Ahmad, Mohammad Shahrul Harris Mohd \\ Shah \\ Section of Chemical Engineering Technology, Universiti Kuala Lumpur Malaysian Institute of Chemical \\ and Bioengineering Technology \\ 1988 Vendor City, Taboh Naning, 78000 Alor Gajah, Melaka, Malaysia \\ *email: nugroho.dewayanto@gmail.com, nugroho@unikl.edu.my
}

\begin{abstract}
Thermal decomposition of empty fruit bunch (EFB), palm kernel shell (PKS) and palm oil milling effluent sludge (POMES) have been investigated. Thermogravimetry analysis was employed to determine the proximate analysis of the samples, and then to study the characteristic of the thermal degradation. Proximate analysis of the sample was conducted by introduce the samples into the TGA and run it under the nitrogen environment from 25 to $800^{\circ} \mathrm{C}$. The gas was shifted to oxygen to let the sample burn and left their ash. Thermal degradation studies were carried out by heating up the samples in TGA from 25 to $800{ }^{\circ} \mathrm{C}$ at different heating ratio. Second order kinetic model was applied to determine the characteristic of the degradation. As the results, the heating rate has no significant effect for the activation energy, which has value range from 31 to $64 \mathrm{~kJ} / \mathrm{mol}$. Lowest activation energy was achieved for POME at heating rate of $10^{\circ} \mathrm{C} / \mathrm{min}(31.1 \mathrm{~kJ} / \mathrm{mol})$, while highest activation energy was for EFB at heating rate of $10^{\circ} \mathrm{C} / \mathrm{min}(63.6 \mathrm{~kJ} / \mathrm{mol})$.
\end{abstract}

Keywords: thermal degradation, biomass, palm oil, thermogravimetry

\section{Introduction}

Global production of oils and fats continue to increase due to the increasing of their worldwide consumption. According to Malaysian Palm Oil Council report, amount of 200.24 million tons of oils and fats were produced around the world in 2014 [1]. From the total production, palm oil and palm kernel dominated by 66.25 tons (33\%), followed by soybean oil and rapeseed oil, contributed 345.14 million tonnes $(23 \%)$ and 26.92 million tonnes (13\%), respectively. Indonesia became the leader of palm oil producer with $51 \%$ share followed by Malaysia with 39\% share of world's palm oil production in 2014 [1]. Existence of oil palm industry in Indonesia and Malaysia gave major contribution for economic growth of the countries. However, palm oil industry commonly generates abundant solid biomass as waste, e.g. empty fruit bunch, palm frond, oil palm fiber, palm kernel shell, also the sludge come from their effluent's aeration ponds. From the processing of fresh fruit bunch (FFB), palm oil milling plant produces $22.8 \mathrm{wt} \%$ as crude palm oil (CPO) and crude palm kernel oil (CPKO) while the rest is released into the environment and considered as by-product and waste [2]. In average, one hectare of palm oil plantation produces about $50-70$ tons biomass residue [3]. The waste potentially causes environmental problem if is not treated and managed properly.

Conversion of biomass into energy becomes one alternative to utilize biomass waste as value-added byproduct. Biomass is recognized as the third largest primary energy source in the world, after coal and oil. It remains the primary source of energy for more than half of the world's population, and provides about 1250 million tons oil equivalent of primary energy, which is about $14 \%$ of the world's annual energy consumption [4]. Traditionally, biomass is utilized to generate energy by direct combustion; it is still practiced until nowadays particularly in developing countries and rural areas. However, direct combustion of palm oil biomasses potentially raises environmental issues related to the gas emission and particulate matters. Therefore, biomass is preferred to be transformed into other types of fuel, e.g. bio-ethanol, bio-oil, syn-gas, hydrocarbon or bio-char prior usage. Several reports on conversion of palm oil biomass into energy sources have been published in the two last decades. Conversion of the empty fruit bunch (EFB) into bio-oil through the thermochemical process was successfully conducted in the fixed bed reactor [5], [6] as well as fluidised bed reactor [7]-[9].

Thermal degradation is the main process in the pyrolysis of biomass. Pyrolysis can be defined as thermal treatment of the substance in absence of the oxygen. Thus, the degradation of the substance is occurred due to the thermal instead of chemical reaction, particularly combustion or oxidation. Most of the thermal degradation 
characteristics can be studied by using thermogravimetry data [10]. Thermogravimetry equipment precisely measures decrease in substrate's mass during the thermal decomposition. Pyrolysis of biomass is a complicated process and involves several chemical reactions. Phase transitions between solid materials into gaseous and liquid products also contribute to the complexity of this process. Several studies had been conducted previously to characterize the biomass pyrolysis, particularly for its kinetic parameters. However, it is difficult to determine the model which is most suitable and consistent for the whole process. This paper aims to present the character of thermal degradation of palm oil milling plant biomass waste by using thermogravimetry data.

\section{Materials and methods}

Empty fruit bunch (EFB), palm kernel shell (PKS), and palm oil milling effluent sludge (POMES) were collected from Kilang Kelapa Sawit Sri Lingga, Melaka. The materials were dried in oven at $105{ }^{\circ} \mathrm{C}$ for overnight to remove the moisture. Dried biomass samples were ground and sieved to obtain the particle size less than $100 \mu \mathrm{m}$. Proximate analysis was conducted by introducing five grams of sample into thermogravimetry analyzer (Mettler Toledo). Sample was heated up from 30 to $800{ }^{\circ} \mathrm{C}$ at heating rate of 20 ${ }^{\circ} \mathrm{C} / \mathrm{min}$ under nitrogen environment. Nitrogen flowrate was $50 \mu \mathrm{L} / \mathrm{min}$. Once the temperature reached $800{ }^{\circ} \mathrm{C}$, nitrogen gas was switched with oxygen gas at $20 \mu \mathrm{L} / \mathrm{min}$, and the heating rate was decreased into $10^{\circ} \mathrm{C} / \mathrm{min}$ until temperature of $900{ }^{\circ} \mathrm{C}$ was reached. Moisture, volatile, and ash contents were determined by analyze the TG profile, while fixed carbon was calculated by difference. Thermal degradation studies were conducted by heating up the samples in TGA from 30 to $800{ }^{\circ} \mathrm{C}$. Various heating rate from 10 to $40{ }^{\circ} \mathrm{C} / \mathrm{min}$ were used in this experiments. Kinetic of the thermal degradation was evaluated by using Coats-Redfern method with second order kinetic models.

\section{Results and discussion}

The purpose of proximate analysis is to determine moisture, volatile, fixed carbon and ash content of materials. It is widely used in solid fuel characterization to show the ratio of combustible and incombustible component, and also to predict the combustion properties of solid fuel for instance its heating value. Proximate analysis is usually conducted by standard method from ASTM such as D1762-84, which was originally developed for analysis of wood charcoal [11]. The TGA plot was divided into 3 stages as shown in Figure 1. In the first stage, the drying process has taken place to remove moisture. Drying process is carried out in temperature range of $25-105{ }^{\circ} \mathrm{C}$. Weight loose in this stage is recognized as moisture content. The second stage is the volatilization of solid in nitrogen atmosphere from 105 to $850{ }^{\circ} \mathrm{C}$. All of volatile matters were degraded in this stage. The third region is the combustion in oxygen environment at $850{ }^{\circ} \mathrm{C}$ to oxidize all fixed carbon content leaving the ash at the end of the process. The fixed carbon was calculated by the summation of percentages of moisture, ash, and volatile matter subtracted from 100 [12]. The proximate analysis for biomass samples were summarized in Table 1 . In general, dried biomass contains about $3-6 \%$ of moisture, while the volatile matter for lignocellulosic biomass in the range of $60-80 \%$. Low composition of volatile and fixed carbon for POMES is because of the sludge contains rich non-organic materials such as sand, clay, minerals, come from the fruit bunch and also impurities during the milling process. It is also indicated by high level of ash content or non-combustible substance $(37.46 \%)$. The proximate composition is in agreement with the results presented by Dewayanto et al. [12] for palm oil milling plant biomass waste collected from Kuantan, Pahang, Malaysia.

Figure 2 illustrates the TGA plot and its first derivative (DTG) plot for EFB (2a), PKS (2b) and POMES (2c). Generally, the weight reduction significantly started at temperature of $200{ }^{\circ} \mathrm{C}$, when the volatile organic compound (VOC) started to volatilize. All of DTG plots shows major peaks at around 200 to $400{ }^{\circ} \mathrm{C}$ indicate that the major decomposition was occurred in those respective temperatures. These typical stages of decomposition were also observed in other biomass thermal degradation such as rapeseed oil cake [13], tobacco rob [14], green algae [15], safflower oil cake [16], empty fruit bunch [17] and cottonseed [18]. At the major decomposition, started from $200{ }^{\circ} \mathrm{C}$ until around $400{ }^{\circ} \mathrm{C}$, the chemical bonds in biomass began to break and the lightest volatile compounds were released. This stage usually corresponds to the thermal decomposition of hemicellulose and cellulose. Under a slow heating regime, the cellulose was found to decompose between 325 and $375{ }^{\circ} \mathrm{C}$ and hemicellulose started to decompose at around $200-300{ }^{\circ} \mathrm{C}$ [14]. Therefore, the first peak in this region is correlated with hemicellulose decomposition, while the second peak corresponds to cellulose decomposition. However, there is no obvious identification of both peaks in POMES, due to the different character of cellulosic materials contained in the sample compare to that of PKS and EFB. There are small decomposition above $400{ }^{\circ} \mathrm{C}$ which is assigned to lignin decomposition and slow degradation of carbonaceous material [15]. For POMES, a peak around $700{ }^{\circ} \mathrm{C}$ is observed, it may be the calcination process of inorganic that evolves carbon dioxide from carbonate decomposition. 


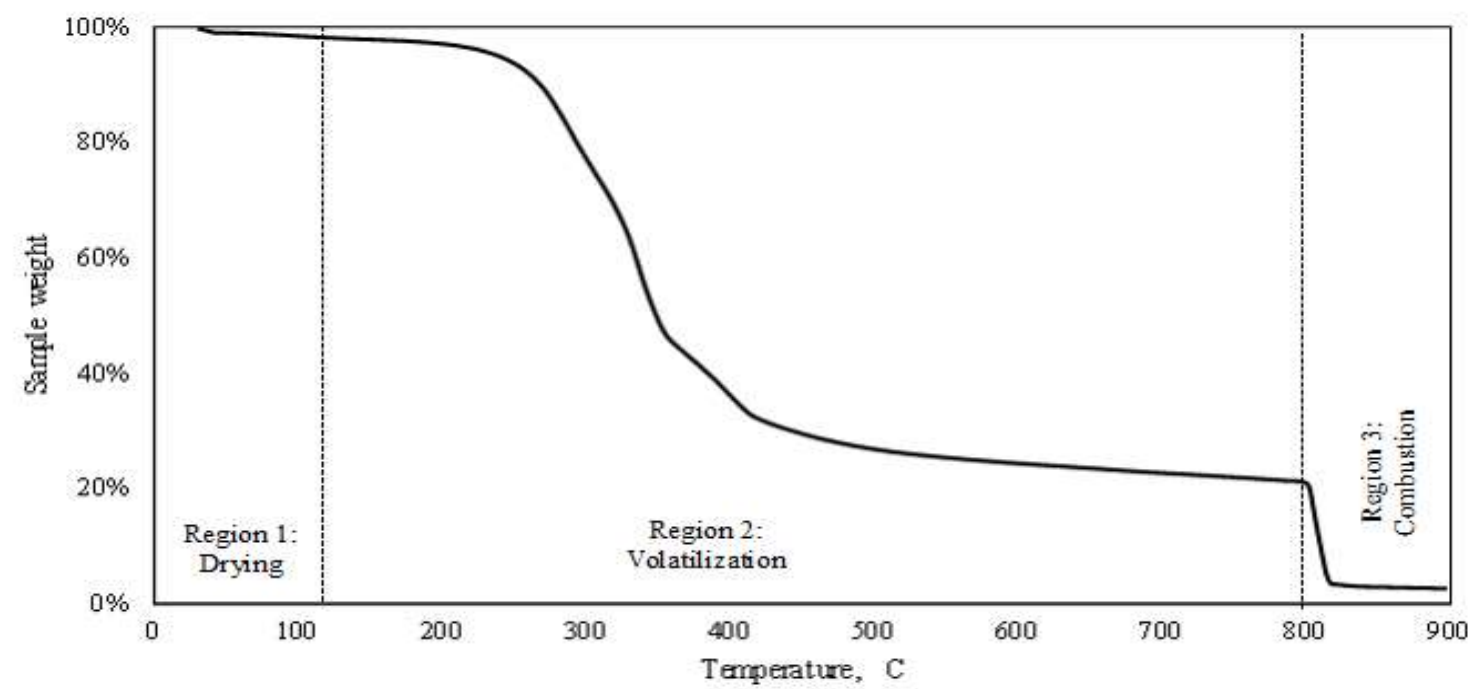

Figure 1. Region division of TGA plot of EFB to determine the proximate composition of sample.

Table 1. Proximate analysis of palm oil milling plant biomass waste

\begin{tabular}{ccccc}
\hline Sample & Moisture, $\%$ & Volatile, $\%$ & Fixed Carbon, $\%$ & Ash, $\%$ \\
\hline EFB & 3.00 & 79.33 & 15.37 & 2.30 \\
PKS & 4.35 & 73.75 & 21.62 & 0.28 \\
POMES & 6.06 & 43.53 & 12.95 & 37.46 \\
\hline
\end{tabular}

The thermogravimetry profile of EFB, PKS and POMES are illustrated in Figure 3. It can be seen that the character of the degradation is not significantly change by increasing the heating rate. However, there is shift of the degradation temperature, and also small change on the degradation rate. A kinetic study has been conducted to investigate effect of heating rate on decomposition rate of biomass sample. Thermal degradation process is a solid complex reaction that cannot be simply characterized by conventional kinetic model. Some isoconversional kinetic model have been developed to make the approach in studying the kinetic of degradation. Using an approach based on isoconversional, where the degree of conversion, $\alpha$, for a reaction is assumed to be constant and therefore the reaction rate, $k$, depends exclusively on the reaction temperature, $T$; Eq. (2.9) can be expressed as [19], [20]:

$$
\frac{d \alpha}{d T}=\frac{A}{\beta} e^{\left(\frac{-E_{a}}{R T}\right)} f(\alpha)
$$

Where $\alpha$ is the extent of the reaction, $\mathrm{T}$ is temperature, $\beta$ is heating rate, $\mathrm{R}$ is universal gas constant, while A, Ea and $f(\alpha)$ are exponential factor, activation energy and kinetic model function, also known as kinetic triplets.

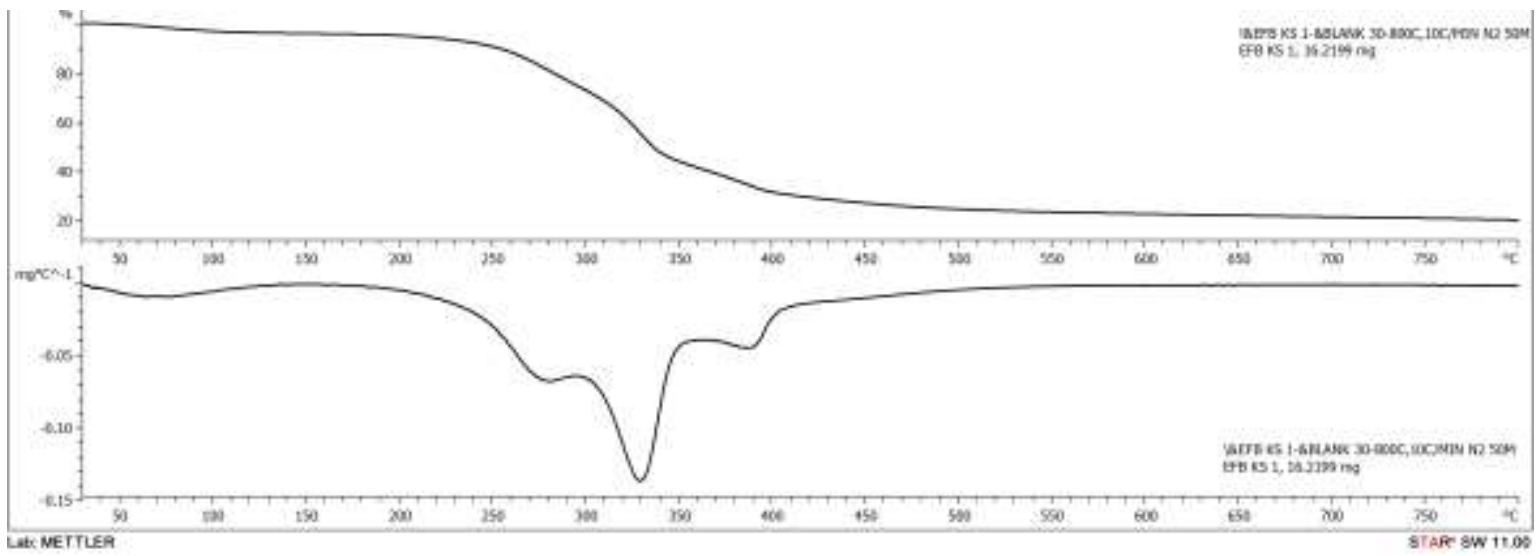

(a) 


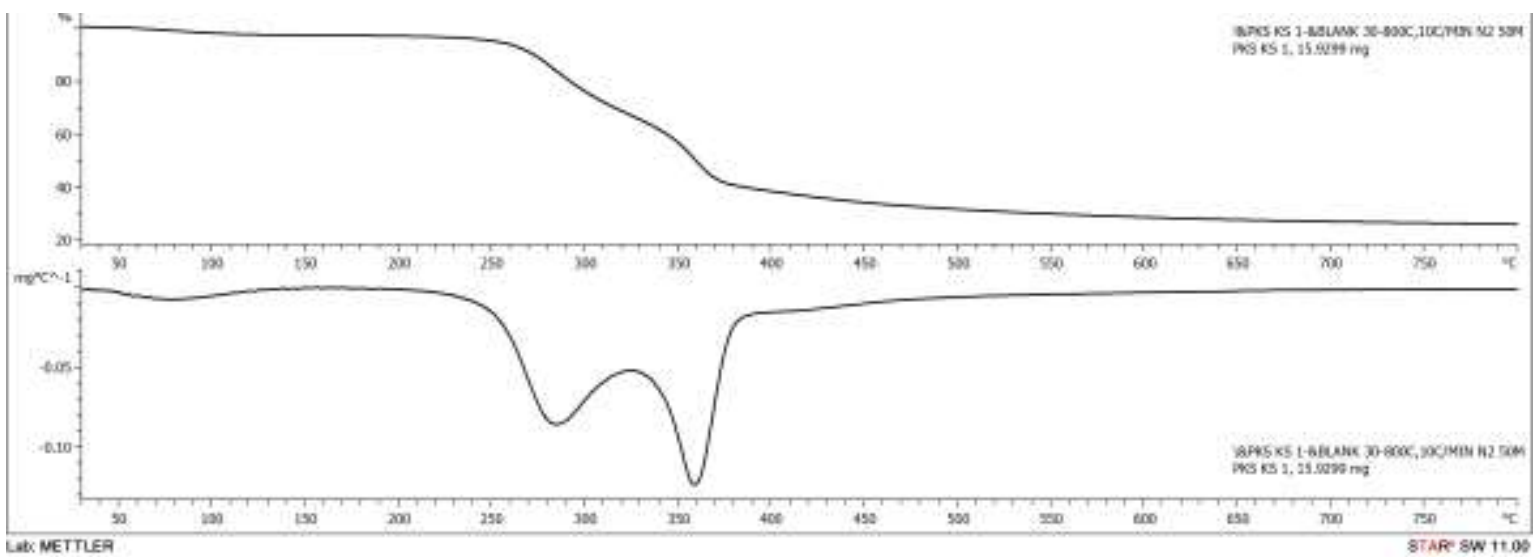

(b)

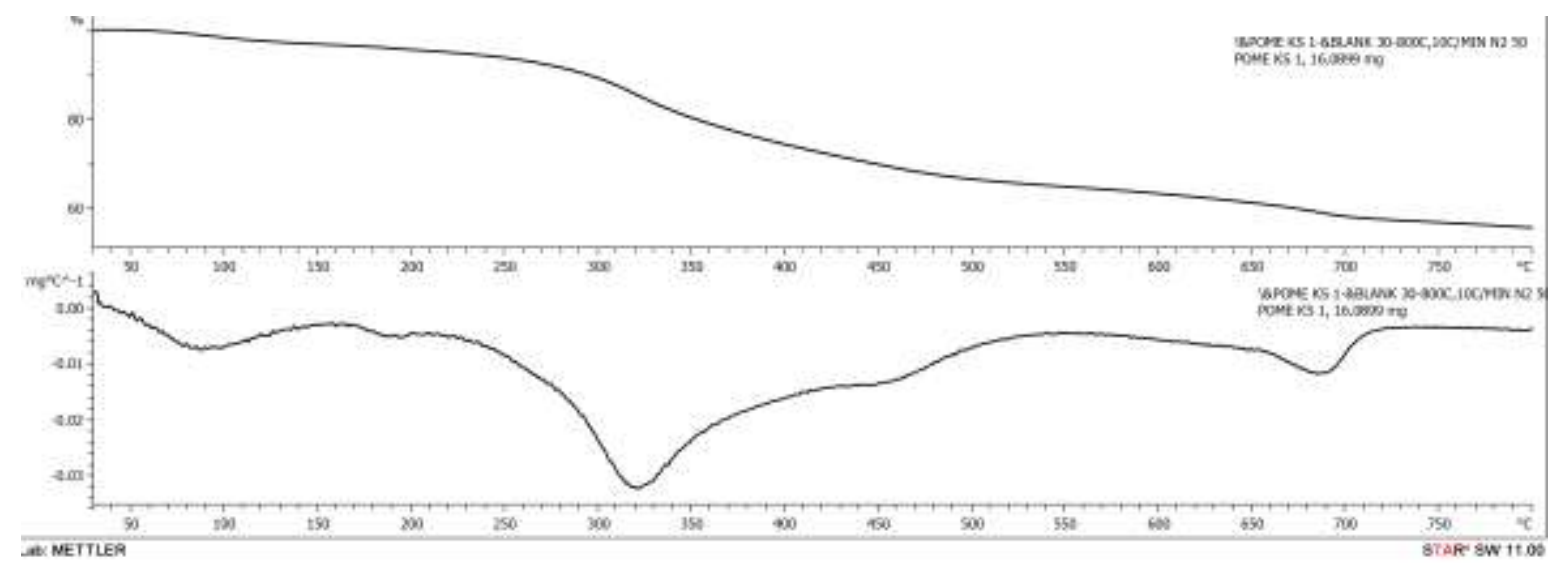

(c)

Figure 2. TGA and DTG plot for EFB (a), PKS (b), and POMES (c) at heating rate of $10{ }^{\circ} \mathrm{C} / \mathrm{min}$

In this paper, a second order kinetic model is used to evaluate the activation energy of thermal degradation of samples. Table 2 summarizes the energy activation of the thermal decomposition process. Basically, the heating rate has no significant effect for the activation energy, which has value range from 31 to $64 \mathrm{~kJ} / \mathrm{mol}$. These values are comparable with other biomass degradation as listed in Table 3 . However, the activation energy of POMES is lowest among the samples, it indicates that POMES require lowest energy to start the degradation process. High correlation coefficient $\left(\mathrm{R}^{2}\right)$ indicates that the second order kinetic model is fit with the experimental data, as shown in Figure 4.

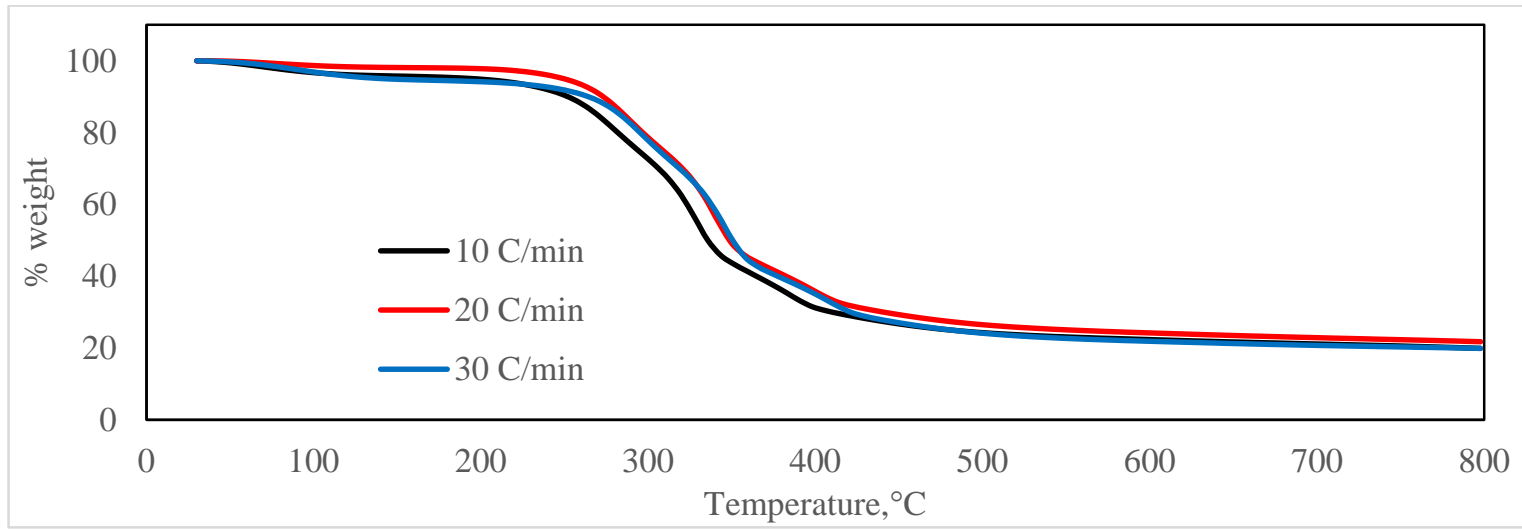

(a) 
Chemica

Volume 3, Nomor 2, Desember 2016, 31-37

ISSN: 2355-8776

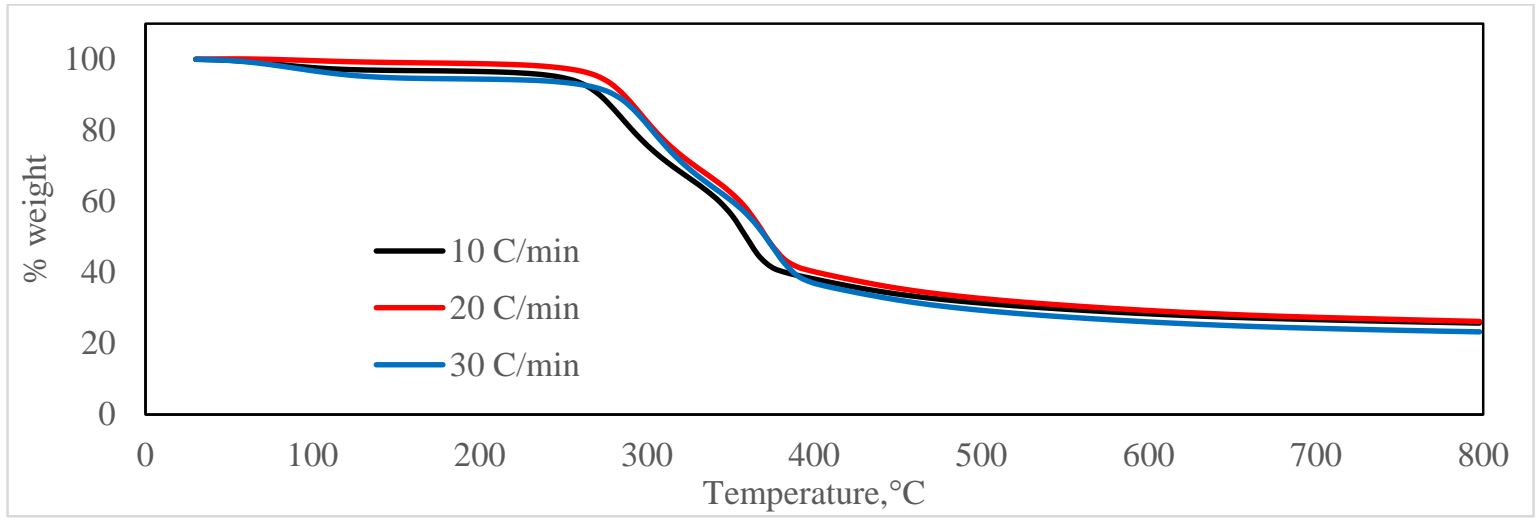

(b)

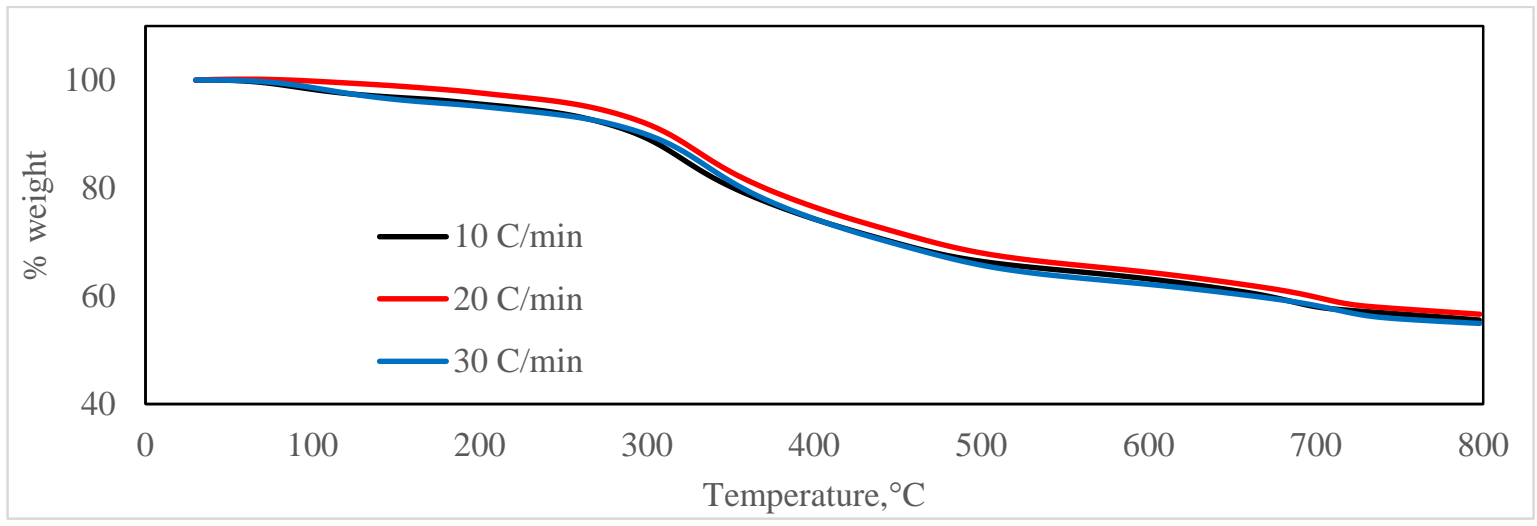

(c)

Figure 3. TGA plot of thermal degradation of EFB (a), PKS (b), and POMES (c) at various heating rate of 10, 20 and 30 ${ }^{\circ} \mathrm{C} / \mathrm{min}$

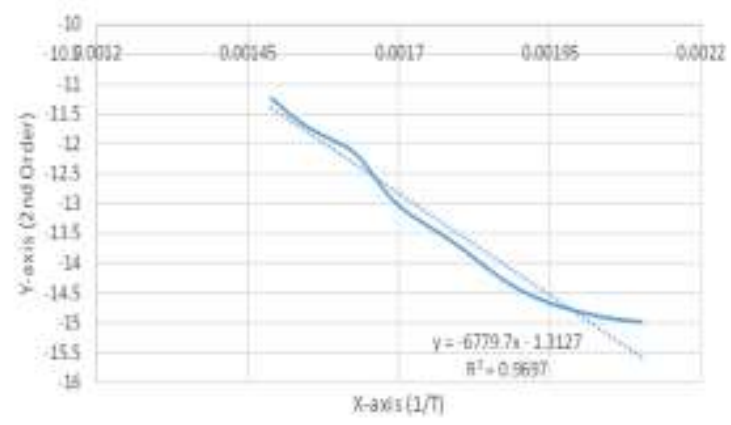

(a)

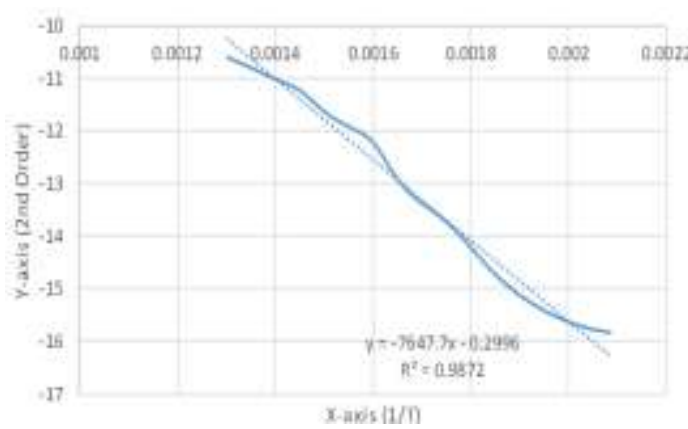

(b)

Figure 4. Second order kinetic models for thermal degradation of EFB at heating rate of (a) $10{ }^{\circ} \mathrm{C} / \mathrm{min}$, and (b) 20 ${ }^{\circ} \mathrm{C} / \mathrm{min}$

Table 2. Kinetic parameter of thermal degradation of palm oil biomasses approached by second order kinetic model.

\begin{tabular}{cccc}
\hline Biomass & $\begin{array}{c}\text { Heating rate, } \\
{ }^{\circ} \mathrm{C} / \mathrm{min}\end{array}$ & $\begin{array}{c}\text { Activation energy, } \\
\mathrm{J} / \mathrm{mol}\end{array}$ & $\begin{array}{c}\text { Correlation } \\
\text { coefficient }\left(\mathrm{R}^{2}\right)\end{array}$ \\
\hline \multirow{2}{*}{ EFB } & 10 & 56366.43 & 0.970 \\
& 20 & 63582.98 & 0.987 \\
\multirow{2}{*}{ PKS } & 30 & 55825.18 & 0.967 \\
& 10 & 48895.47 & 0.967 \\
\multirow{2}{*}{ POMES } & 20 & 61277.51 & 0.961 \\
& 30 & 46663.99 & 0.980 \\
& 10 & 31147.57 & 0.998 \\
& 20 & 36066.13 & 0.996 \\
& 30 & 31795.23 & 0.989 \\
\hline
\end{tabular}


Table 3. Activation energy of biomass degradation

\begin{tabular}{cccccc}
\hline Biomass & T range, ${ }^{\circ} \mathrm{C}$ & Reaction model & $\begin{array}{c}\mathrm{Ea}, \\
\mathrm{kJ} / \mathrm{mol}\end{array}$ & A, $\mathrm{min}^{-1}$ & Reference \\
\hline Wheat straw & $200-350$ & $\begin{array}{c}\text { 2 dimensional } \\
\text { diffusion }\end{array}$ & 172 & $10^{12}$ & {$[21]$} \\
& $350-500$ & $1^{\text {st }}$ order reaction & 154 & $10^{11}$ & \\
Cardoon leaves & $200-320$ & $1^{\text {st }}$ order reaction & 169.7 & $5.2 \times 10^{16}$ & {$[22]$} \\
& $280-380$ & $1^{\text {st }}$ order reaction & 92.6 & $2.8 \times 10^{7}$ & \\
Pine wood & $200-600$ & $1^{\text {st }}$ order reaction & 36.1 & 28 & \\
& $283-390$ & $1^{\text {st }}$ order reaction & 68.5 & $4.0 \times 10^{19}$ & {$[23]$} \\
EFB & $385-608$ & $1^{\text {st }}$ order reaction & 45.2 & $1.3 \times 10^{6}$ & \\
& $307-378$ & 3-D diffusion & 55.4 & $7.9 \times 10^{7}$ & \\
\hline
\end{tabular}

\section{Conclusion}

In this experiment, thermogravimetry data was successfully employed to determine the proximate composition of empty fruit bunch, palm kernel shell and palm oil milling effluent sludge. The composition of the biomasses in this study were similar with the typical proximate composition of biomass. Therefore, it can be concluded that the utilization of thermogravimetry data to analyze the proximate composition of biomass is acceptable. Thermal degradation of EFB, PKS and POME are started at around $200{ }^{\circ} \mathrm{C}$, when the hemicellulose was started to be decomposed. The degradation continued until almost all of the lignin content was degraded at temperature above $400{ }^{\circ} \mathrm{C}$. The kinetic of the major degradation at range of 200 to $400{ }^{\circ} \mathrm{C}$ can be fitted with second order kinetic model. The model was fitted with all of the heating rate of the degradation, with correlation coefficients are above 0.96 . Activation energy of the major thermal degradation are within the range of 31 to $64 \mathrm{~kJ} / \mathrm{mol}$.

\section{References}

[1] MPOC, “Annual Report 2014,” Malaysian Palm Oil Counc., pp. 1-164, 2014.

[2] O. Chavalparit, W. H. Rulkens, A. P. J. Mol, and S. Khaodhair, "Options for environmental sustainability of the crude palm oil industry in Thailand through enhancement of industrial ecosystems," Environ. Dev. Sustain., vol. 8, no. 2, pp. 271-287, Mar. 2006.

[3] S. H. Shuit, K. T. Tan, K. T. Lee, and A. H. Kamaruddin, "Oil palm biomass as a sustainable energy source: A Malaysian case study,” Energy, vol. 34, no. 9, pp. 1225-1235, Sep. 2009.

[4] L. Chen, L. Xing, and L. Han, "Renewable energy from agro-residues in China: Solid biofuels and biomass briquetting technology," Renew. Sustain. Energy Rev., vol. 13, no. 9, pp. 2689-2695, 2009.

[5] X. Y. Lim and J. M. Andrésen, "Pyro-catalytic deoxgenated bio-oil from palm oil empty fruit bunch and fronds with boric oxide in a fixed-bed reactor," Fuel Process. Technol., vol. 92, no. 9, pp. 1796-1804, Sep. 2011.

[6] M. Misson, R. Haron, M. F. A. Kamaroddin, and N. A. S. Amin, "Pretreatment of empty palm fruit bunch for production of chemicals via catalytic pyrolysis.," Bioresour. Technol., vol. 100, no. 11, pp. 2867-73, Jun. 2009.

[7] F. Sulaiman and N. Abdullah, "Optimum conditions for maximising pyrolysis liquids of oil palm empty fruit bunches,” Energy, vol. 36, no. 5, pp. 2352-2359, May 2011.

[8] N. Abdullah and H. Gerhauser, "Bio-oil derived from empty fruit bunches," Fuel, vol. 87, no. 12, pp. 2606-2613, Sep. 2008.

[9] N. Abdullah, H. Gerhauser, and F. Sulaiman, "Fast pyrolysis of empty fruit bunches," Fuel, vol. 89, no. 8, pp. 2166-2169, 2010.

[10]N. Dewayanto, R. Isha, and M. R. Nordin, "Kinetic study on the catalytic pyrolysis of decanter cake from palm oil milling plant by using thermogravimetry data," J. Teknol. (Sciences Eng., vol. 69, no. 5, 2014.

[11]D. Aller, S. Bakshi, and D. A. Laird, "Modified method for proximate analysis of biochars," J. Anal. Appl. Pyrolysis. 
[12]N. Dewayanto, M. H. M. Husin, and M. R. Nordin, "Solid fuels from decanter cake and other palm oil industry waste," J. Teknol., vol. 76, no. 5, 2015.

[13]K. Smets, P. Adriaensens, G. Reggers, S. Schreurs, R. Carleer, and J. Yperman, "Flash pyrolysis of rapeseed cake: Influence of temperature on the yield and the characteristics of the pyrolysis liquid," $J$. Anal. Appl. Pyrolysis, vol. 90, no. 2, pp. 118-125, Mar. 2011.

[14]Y. Yang, T. Li, S. Jin, Y. Lin, and H. Yang, "Catalytic pyrolysis of tobacco rob: kinetic study and fuel gas produced.," Bioresour. Technol., vol. 102, no. 23, pp. 11027-33, Dec. 2011.

[15]S. Thangalazhy-Gopakumar, S. Adhikari, S. A. Chattanathan, and R. B. Gupta, "Catalytic pyrolysis of green algae for hydrocarbon production using H+ZSM-5 catalyst.," Bioresour. Technol., vol. 118, pp. 150 7, Aug. 2012.

[16]G. Duman, M. Pala, S. Ucar, and J. Yanik, “Two-step pyrolysis of safflower oil cake,” J. Anal. Appl. Pyrolysis, vol. 103, pp. 352-361, Sep. 2013.

[17]M. A. A. Mohammed, A. Salmiaton, W. A. K. G. Wan Azlina, and M. S. M. Amran, "Gasification of oil palm empty fruit bunches : A characterization and kinetic study," Bioresour. Technol., vol. 110, pp. 628636, 2012.

[18]E. Apaydin-Varol and E. Pütün, "Synthetic fuel production from cottonseed : Fast pyrolysis and a TGA / FT-IR / MS study,” J. Anal. Appl. Pyrolysis, vol. 105, pp. 83-90, 2014.

[19]S. Vyazovkin and C. A. Wight, "Model-free and model-fitting approaches to kinetic analysis of isothermal and nonisothermal data," Thermochim. Acta, vol. 340-341, pp. 53-68, 1999.

[20]S. Kim and Y. Eom, "Estimation of kinetic triplet of cellulose pyrolysis reaction from isothermal kinetic results," Korean J. Chem. Eng., vol. 23, no. 3, pp. 409-414, 2006.

[21]C. Lu, W. Song, and W. Lin, "Kinetics of biomass catalytic pyrolysis," Biotechnol. Adv., vol. 27, no. 5, pp. 583-587, 2009.

[22]T. Damartzis, D. Vamvuka, S. Sfakiotakis, and A. Zabaniotou, "Thermal degradation studies and kinetic modeling of cardoon (Cynara cardunculus) pyrolysis using thermogravimetric analysis (TGA).," Bioresour. Technol., vol. 102, no. 10, pp. 6230-8, May 2011.

[23]P. Pimenidou and V. Dupont, "Characterisation of palm empty fruit bunch (PEFB) and pinewood bio-oils and kinetics of their thermal degradation.," Bioresour. Technol., vol. 109, pp. 198-205, Apr. 2012. 